\title{
NOVO ENSAIO DE COMBATE QUIMICO AO ACARO DA LEPROSE DOS CITROS Brevipalpus phoenicis (GEIJSKES, 1939) EM LARANJEIRAS
}

\author{
F.Y. Arashiro* \\ A.J. Raizer* \\ C.A. Sugahara* \\ R. Mota* \\ J.M. Silva* \\ F.A.M. Mariconi**
}

RESUMO: o ácaro da leprose Brevipalpus phoenicis (Geijskes, 1939) é o vetor responsāvel pela transmissão do agente causador da leprose em laranjeiras, possive1mente um vírus. A doença é grave, responsảvel por grandes perdas nos laranjais paulistas. Este trabalho foi realizado com o objetivo de combate a esse äcaro com a aplicação de defensivos químicos. Tratamentos: A) testemunha; B) fempropatrina $(13,5 \mathrm{~g})$; C) clofentezina $(20,0 \mathrm{~g})$; D) bifentrina $(5,6 \mathrm{~g})$; E) binapacril $(50,0 \mathrm{~g})$; F) flubenzimina $(60,0 \mathrm{~g}) ; \mathrm{G})$ ciexatina $(20,0 \mathrm{~g})$. As quantidades entre parenteses são de ingrediente ativo para 100 litros de água. Gastaram-se 4 litros de calda por ärvore e 1.332 litros por hectare. A ciexatina, binapacril e bifentrina foram os tratamentos mais eficientes, principalmente a ciexatina.

* Bolsistas do Departamento de Zoologia da E.S.A."Luiz de Queiroz", da Universidade de São Paulo - 13.400 Piracicaba, SP.

** Departamento de Zoologia da E.S.A."Luiz de Queiroz", da Universidade de São Paulo-13.400-Piracicaba, SP. 
Termos para indexação: àcaro de leprose, Brevipalpus phoenicis, defensivo agrícola, fruta cítrica.

NEW FIELD TEST FOR CHEMICAL CONTROL OF THE CITRUS LEPROSIS MITE Brevipalpus phoenicis (GEIJSKES, 1939) ON ORANGE-TREES

ABSTRACT: In order to evaluate the performance of several chemicals to control the citrus leprosis mite on orange-trees a test was performed in Rio das $\mathrm{Pe}$ dras, State of São Paulo, Brazil. The treatments were as follows: A) control; B) fenpropathrin, $13.5 \mathrm{~g}$; C) clofentezine, 20.og; D) biphenthrin, 5.6g: E) binapacryl, $50.0 \mathrm{~g}$; F) flubenzimine $60.0 \mathrm{~g} ; \mathrm{G}$ ) ciexathin, $20.0 \mathrm{~g}$. The amounts above are in active ingredients per 100 liters of water. Each orange-tree received 4.0 liters of liquid (1332 liters/hectare). Seven evaluations of the mite infestation were made on fruits: the first, one day before and $02,15,30,44,65$ and 79 days after spray. The best results were obtained in the treatments with ciexathin, binapacryl and biphenthrin.

Index terms: citrus leprosis mite, Brevipalpus phoenicis, pesticide, citrus.

\section{INTRODUÇAOO}

Considerada uma das principais doenças da laranjeira doce, uma vez que o agente causador infecta severamente folhas, ramos e frutos, a leprose requer sem dúvida, especial atenção dos meios de pesquisa. o agente desfigura os frutos, promovendo sua queda, reduzindo muito o valor comercial da produção dos pomares atacados. Produz também lesões externas e profundas nos ramos e galhos, cuja morte é provocada direta ou 
indiretamente. Vejamos algumas informações. SUPLICY FILHO et $a$ li $i$ (1977) obtêm resultados bons e semelhantes com o enxofre e dicofol; o clorobenzilato foi um pouco inferior. MARICONI et alii (1979) experimentam o triazofós, etiom, carbofenotiom e fentiom, mas os resultados não foram promissores. SILVA et alii (1983) obtêm as maiores reduçôes populacionais do äcaro da leprose com dicofol + tetradifom, dicofol e flubenzimina. CHIAVEGATO \& YAMASHITA (1984) verificam que a aver mectina conduziu a excelentes resultados, que pouco di= feriram dos padrões utilizados (bromopropilato e dicofol). Observam tambēm que a adição de um ōleo mineral a esse produto não alterou o seu comportamento. OLIVEIRA (1986a) constata que a abamectina (avermectina MK 936), aplicada isoladamente ou em mistura com óleo, e o dicofol mantiveram baixa a população do ācaro e tambēm que o clorobenzilato foi ineficiente. OLIVEIRA (1986b) verifica a boa atuação do binapacril, bromopropilato, binapacril + teflurom, hexitiazox, oxido de fembutatina e ciexatina mas, que o dicofol apōs 30 dias, não è eficiente. SILVA et alii (1986) obtêm ótimos resultados de combate, até 38 dias da aplicação com a ciexatina, quinometionato, flubenzimina e bromopropilato; entretanto, ainda aos 58 dias da aplicação, o bromopropilato deu $100 \%$ de mortalidade do ácaro.

Com o objetivo de aumentar os conhecimentos de combate químico instalou-se o presente trabalho, que passamos a descrever.

\section{MATERIAL E METODOS}

Local: campo experimental instalado no Sítio das Palmeiras, município de Rio das Pedras, Estado de São Paulo, de propriedade do Sr. Antônio Domingos Falcade.

Pomar: formado de laranjeiras "Natal", com aproximadamente 7 anos de idade, que apresentavam boa carga de frutos maduros. Os espaçamentos entre plantas e entre linhas eram, respectivamente, de 4,00 e 7,50m 
(portanto, 333 laranjeiras por hectare).

Tratamentos: em número de sete, com quatro repetições cada. Foi adotado o método de blocos casualizados; havia, portanto, 28 parcelas (canteiros), sendo que cada uma delas era constituída por três laranjeiras (12 plantas por tratamento). Os tratamentos, produtos comerciais ou experimentais, formulações, concentrações e consumo de material encontram-se na Tabela 1 .

Aplicação: realizada em 10 de julho de 1986, com pulverizadores costais motorizados. Cada parcela recebeu 12,0 litros de calda (4,0 litros por laranjeira). Apesar dos aparelhos terem tanque com capacidade para 12,0 litros, somente metade da calda era colocada e pul verizada de um dos lados das três laranjeiras; esgotada a carga, repetia-se a operação com os 6,0 1itros restantes no outro lado das mesmas, que ainda não havia si do pulverizado. Deste modo, garantia-se uma aplicação uniforme em todas as parcelas. Foi usado o espalhante-adesivo "Extravon", na dose de $20 \mathrm{~cm}^{3} / 100$ litros de calda.

Amostragens: as contagens foram realizadas no cam po. Em cada avaliação foram coletados 5 frutos por planta util, a central das 3 laranjeiras de cada parce1a (20 frutos por tratamento). Foram apanhadas laranjas maduras e com sintomas de verrugose, distribuídas por toda a volta das plantas. Em cada fruto, marcaramse quatro áreas com vazador no 12 ( cada ārea $=2,27 \mathrm{~cm}^{2}$ ) sobre as regióes que apresentavam verrugose e nelas foram contados tanto os ácaros da leprose, como seus ácaros predadores. As coletas de laranja foram sete: a prévia, feita em 09 de julho (01 dia antes da aplicação), e as demais, realizadas em 12 e 25 de julho (02 e 15 dias após a pulverização), 09 e 23 de agosto (30 e 44 dias após) e, finalmente, 13 e 27 de setembro de 1986 (65 e 79 dias após). Como foi dito, as contagens foram realizadas no campo: para isso, usaram-se estereoscópicos sob o aumento de 20 vezes. Para cada microscópio havia uma mesinha e um banquinho giratório. 


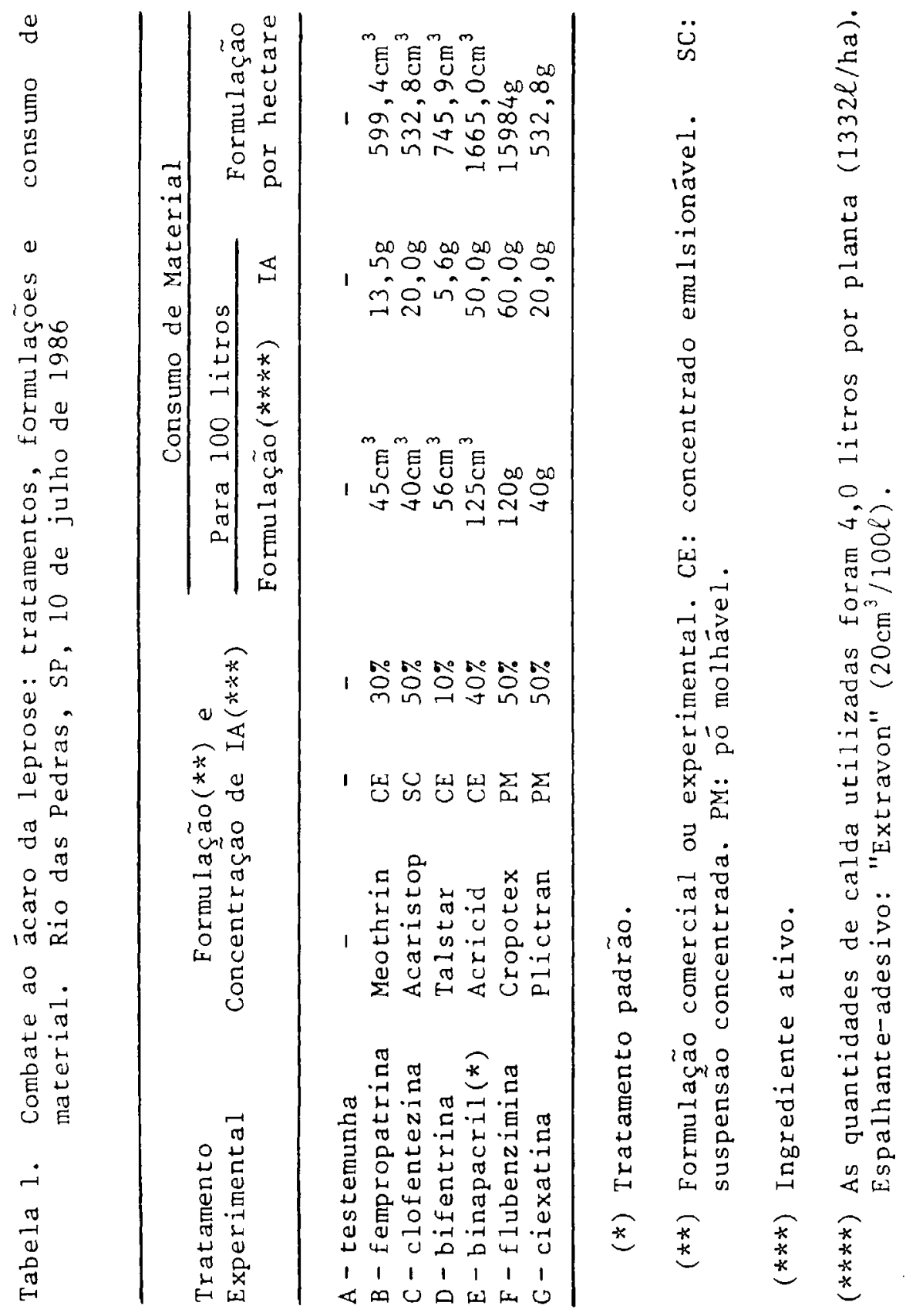


Populações: as populações do ācaro de leprose em cada avaliação podem ser vistas na Tabela 2. Da mesma maneira, pode-se observar na Tabela 5 que, a população dos ácaros predadores do ácaro da leprose foi, na maior parte das vezes, igual a zero.

Análise estatística: as populações do ácaro foram transformadas em $\sqrt{x+0,5}$ sendo $x$ o numero de ácaros de cada parcela, em cada contagem. Os resultados foram submetidos à análise pelo teste " $F$ " $e$, se apurada signi ficância, procedeu-se à anālise das médias pelo testé de "Tukey", ao nível de 5\%. O coeficiente de variação para cada avaliação também foi estimado, e os resultados são mostrados na Tabela 4.

Redução real ou eficiência: foi calculada pela fórmula de "Abbott", tomando-se por base a população de ácaros de cada tratamento, transformada em porcentagem de sobrevivência. Os dados podem ser observados na Tabela 3 .

\section{RESULTADOS E DISCUSSAO}

Vejamos, com base na análise estatística, ao nível de $5 \%$ de probabilidade, e na redução real, os principais resultados. Contagem prévia (01 dia antes da pulverização): os tratamentos não diferem estatisticamente entre si; la e 2 2 contagens (02 e 15 dias após a pulverização): não se observa diferença estatística entre os tratamentos; 3 a 4 a contagens ( 30 e 44 dias após): os tratamentos D (bifentrina), E (binapacril) e G (ciexatina) diferem da testemunha, apresentando reduçoes reais acima de $90 \%$; 5 a contagem (65 dias após): somente o tratamento $G$ (ciexatina) difere estatisticamente da testemunha, atingindo sua mäxima eficiēncia $(98,4 \%) ; 6^{a}$ contagem ( 79 dias apōs): os tratamentos B (fempropatrina) e $G$ (ciexatina) diferem da testemunha, com eficiências de $83,8 \%$ e $90,8 \%$ respectivamente.

Deve-se notar que a bifentrina (FMC 54800) não produziu desequilíbrio biológico, ao contrário do que 


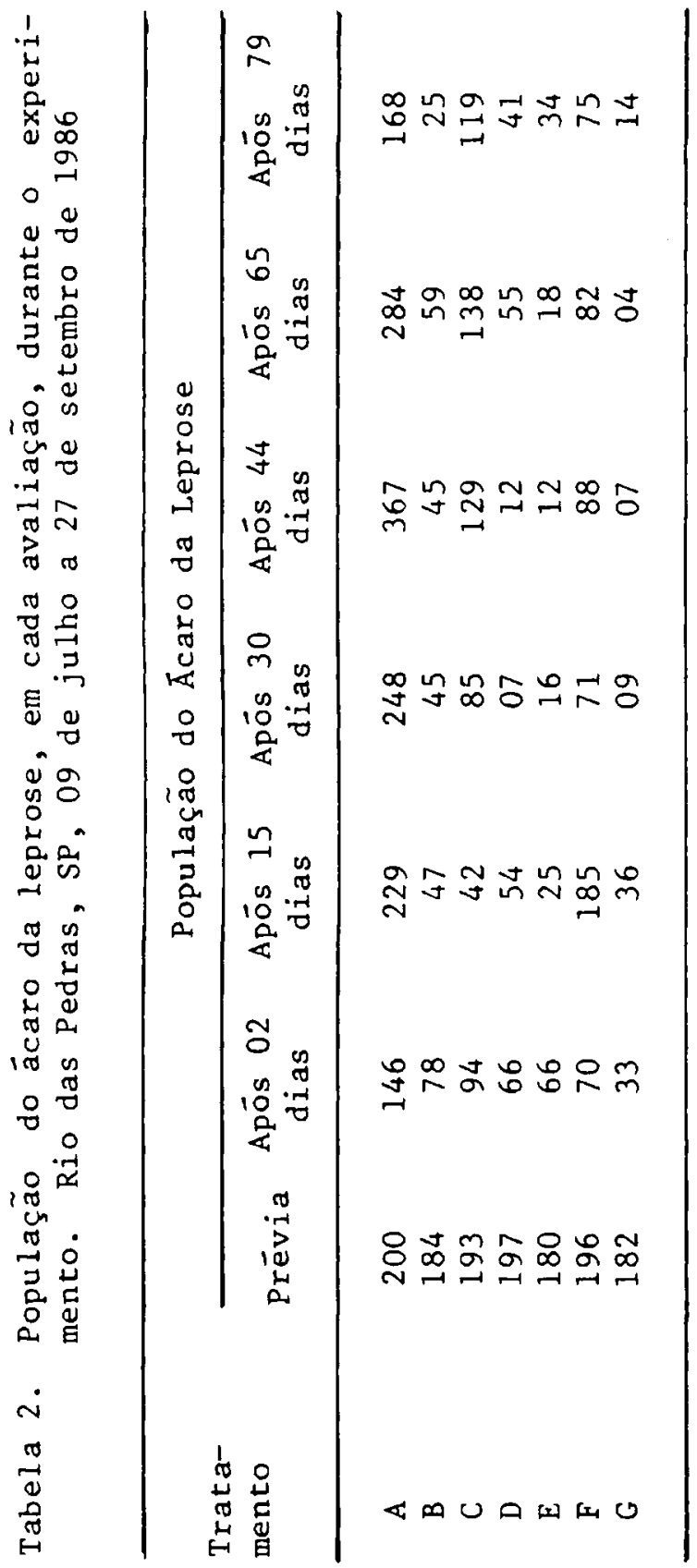




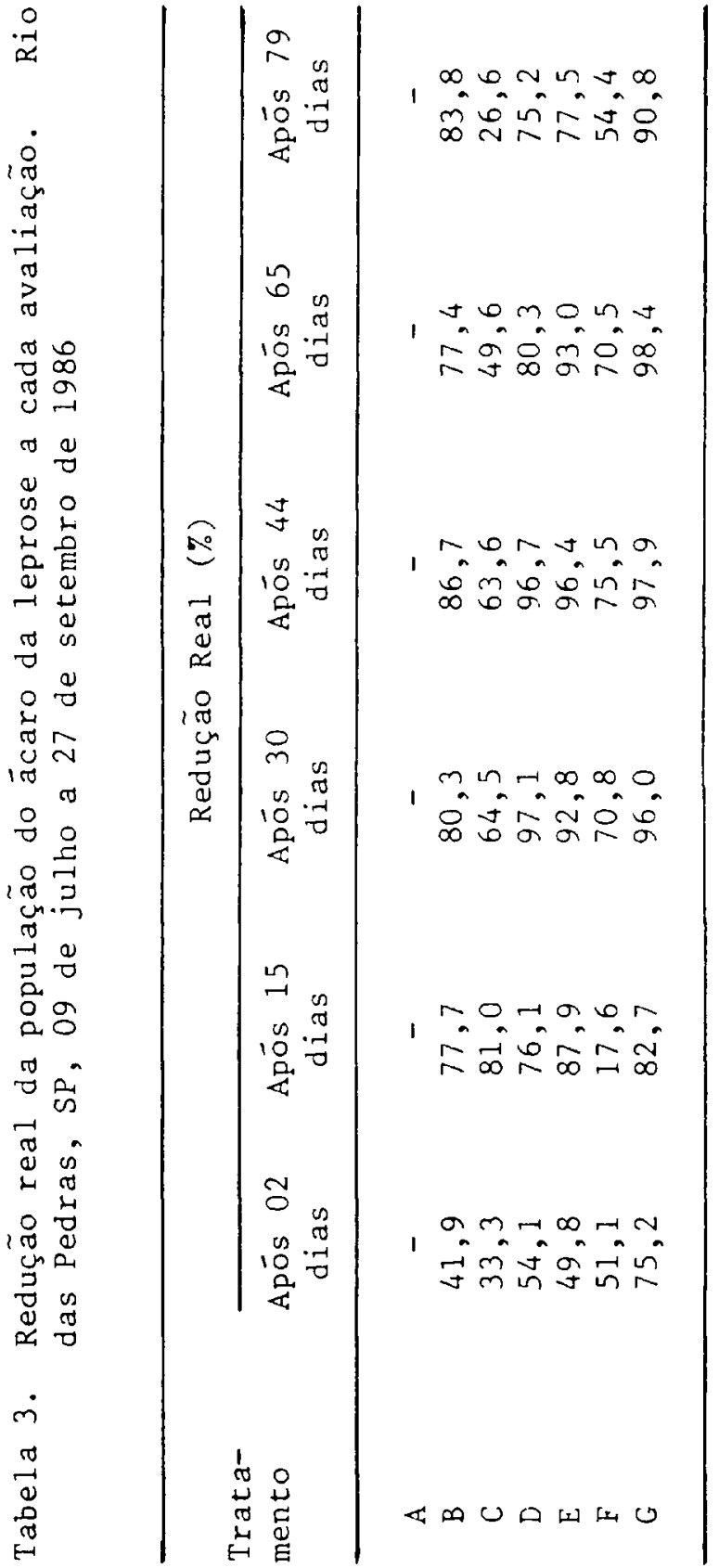




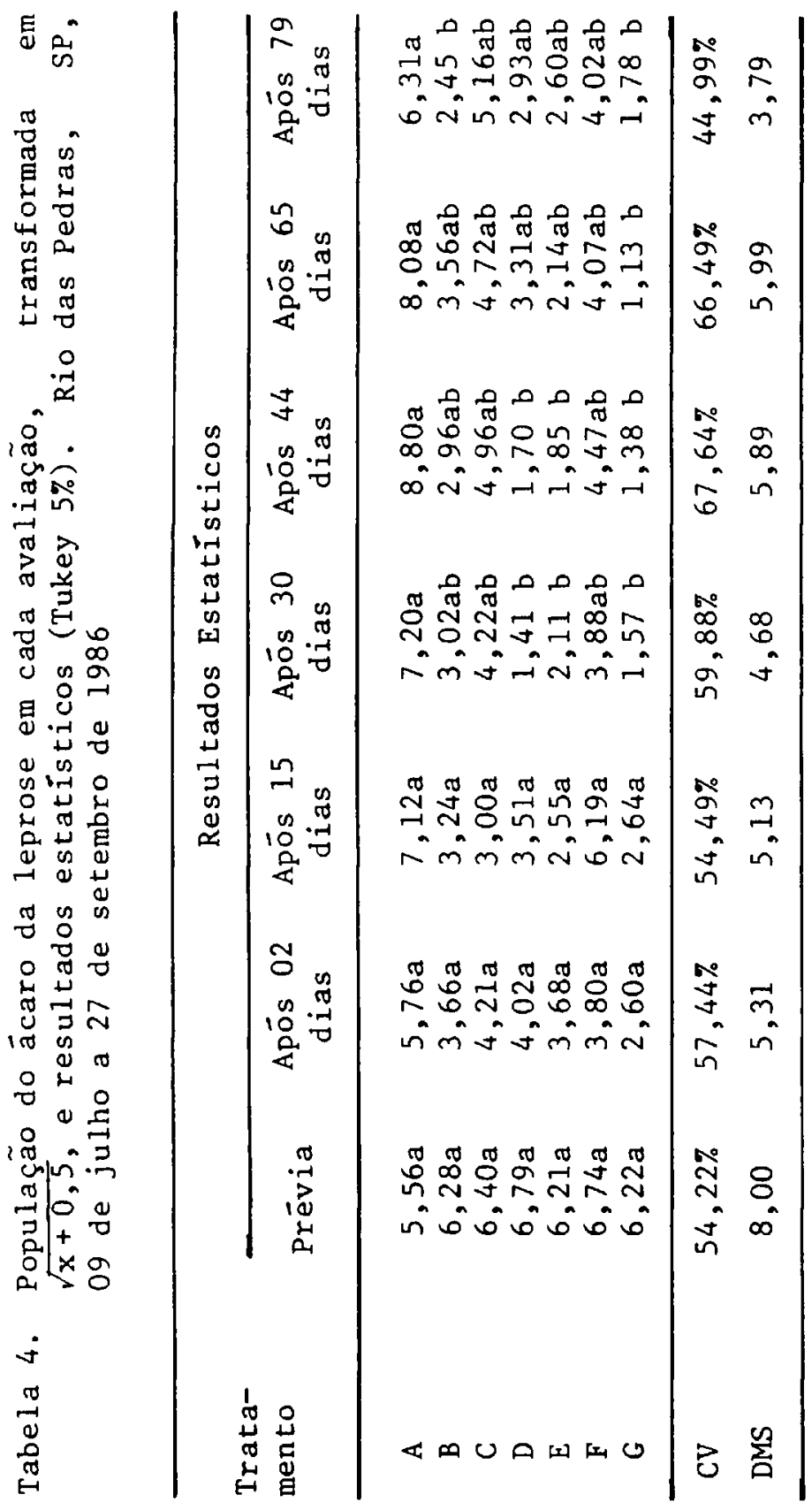




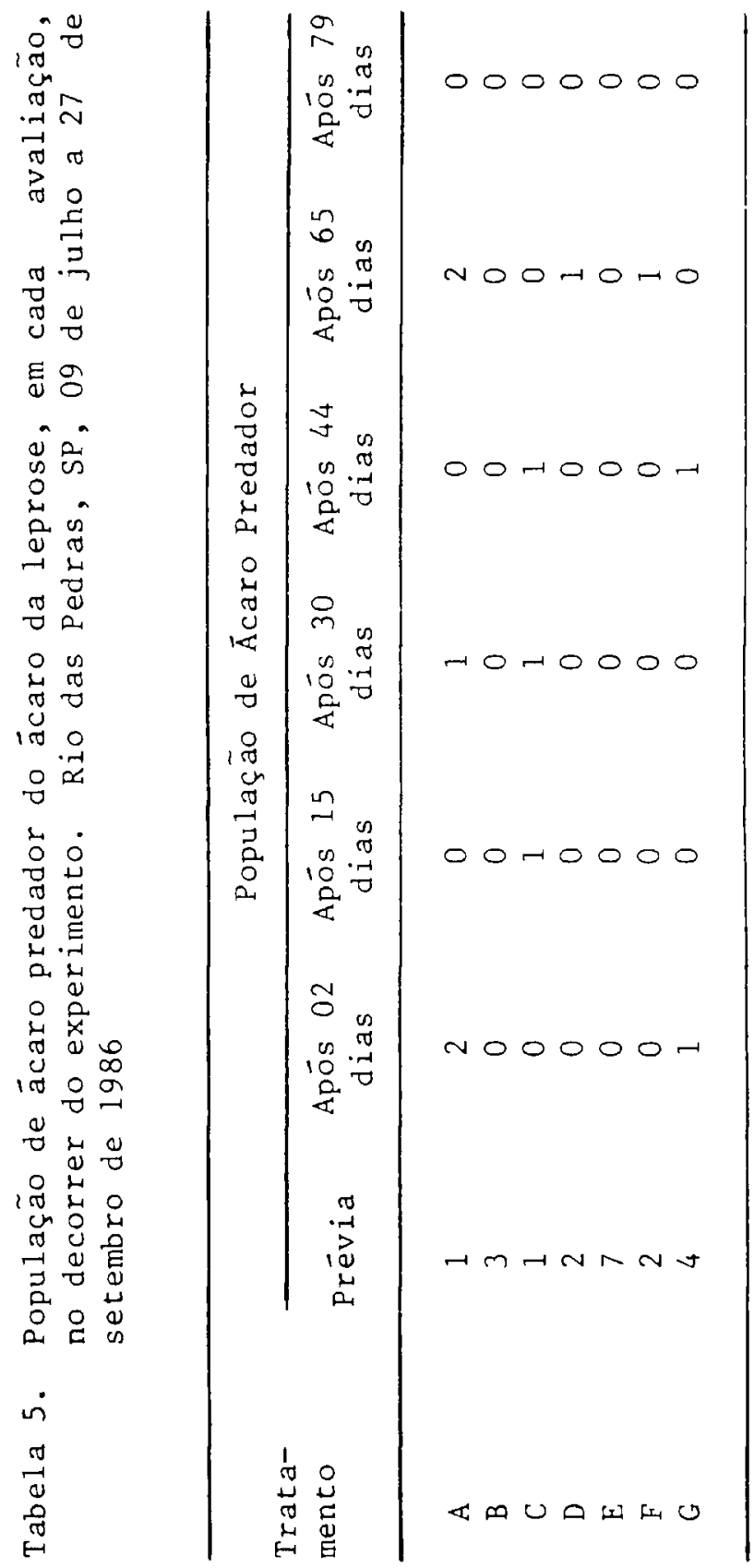


sucedeu em outro trabalho (ALMEIDA et alii, 1981).

\section{CONCLUSOES}

1. Verificou-se durante o experimento que os tramentos com ciexatina, binapacril e bifentrina conduziram aos melhores resultados, destacando-se a ciexatina, cujo efeito residual foi mais longo.

2. A fempropatrina e a flubenzimina apresentaram resultados considerados razoavelmente bons, mas a clofentezina mostrou-se pouco eficiente.

\section{REFERENCIAS BIBLIOGRAFICAS}

ALMEIDA, S.L.; CORTE, C.R.; MORAIS, A.A.; GALHARDO, L. C.S.; FEKETE, T.J.; MARICONI, F.A.M. Defensivos quí micos e o fungo Hirsutella thompsonii (Fisher, 1950) pulverizados contra Phyllocoptruta oleivora (Ashm., 1879) (ácaro da falsa ferrugem dos citros). O Solo, Piracicaba, 73(2):11-7, 1981.

CHIAVEGATO, L.G. \& YAMASHITA, J. Efeito de avermectina (MK-936) sobre o àcaro da leprose Brevipalpus phoenicis (Geijskes, 1939) (Acari-Tenuipalpidae) em citros. In: CONGRESSO BRASILEIRO DE ENTOMOLOGIA, 9., Londrina, 1984. Resumos. Londrina, 1984. p.277.

MARICONI, F.A.M.; CARVALHO, J.C.; OLIVEIRA FILHO, J.C.; SANTOS, B.M.; FAGAN, R.; BRUNELLI JUNIOR, H.C.; AMORIM NETO, L.A. Combate químico ao ácaro da leprose Brevipalpus phoenicis (Geijskes, 1939) em laranjeiras. O Solo, Piracicaba, 71(1):13-6, 1979.

OLIVEIRA, C.A.L. Controle dos ácaros da ferrugem Phyllocoptruta oleivora (Ashmead, 1836) e da leprose Brevipalpus phoenicis (Geijskes, 1939) com avermecti na em citros. In: CONGRESSO BRASILEIRO DE ENTOMOLOGIA, 10., Rio de Janeiro, 1986. Resumos. Rio de Janeiro, 1986a. p.264. 
OLIVEIRA, C.A.L. Acaricidas no controle do ácaro da leprose Bravipalpus phoenicis (Geijskes, 1939)(Acari: Tenuipalpidae) na cultura do citros: In: CONGRESSO BRASILEIRO DE ENTOMOLOGIA, 10., Rio de Janeiro, 1986. Resumos. Rio de Janeiro, 1986b. p.338.

SILVA, J.M.; RAIZER, A.J.; SUGAHARA, C.A.; MOTTA, R.; MARICONI, F.A.M.; SCARPARI FILHO, J.A. Ensaio de combate químico ao ácaro da leprose Brevipalpus phoe nicis (Geijskes, 1939) em pomar citrico. Anais da Escola Superior de Agricultura "Luiz de Queiroz", Pi racicaba, 43:551-63, 1986.

SILVA, J.R.T.; RIZOTTO, E.L.; OLIVEIRA, C.A.L.; Eficiência de produtos com ação acaricida no controle do ácaro da leprose Brevipalpus phoenicis (Geijskes, 1939) (Acari: Tenuipalpidae) em citros. In: CONGRESSO BRASILEIRO DE ENTOMOLOGIA, 8., Brasília, 1983. Resumos. Brasília, 1983. p.110.

SUPLICY FILHO, N.; CINTRA, A.F.; MYAZAKI, I.; OLIVEIRA, D.A.; TEOFILO SOBRINHO, J. Comportamento do "ácaro da leprose" Brevipalpus phoenicis (Geijskes, 1939) em relação a alguns acaricidas na zona de Limeira. O Biológico, São Paulo, 43(1/2):21-4, 1977.

Recebido para publicação em: 23/12/87.

Aprovado para publicação em: 16/03/88. 